\title{
Avaliação da Eficácia das Estratégias de Posicionamento e do Nível de Atratividade Setorial, do Ponto de Vista do Acionista ${ }^{(1)}$
}

\author{
Rodrigo Bandeira de Mello \\ Rosilene Marcon
}

\begin{abstract}
Resumo
Grande parte da literatura sobre estratégia competitiva ressalta, como principal objetivo empresarial, a obtenção de retornos acima da média. No Brasil, pesquisas empíricas que visam mensurar os retornos anormais setoriais e relacioná-los às questões estratégicas não têm recebido a atenção devida. Esta pesquisa, fundamentada principalmente na tradição da Organização Industrial, apresenta os resultados de um estudo exploratório e longitudinal, baseado em dados objetivos coletados no período de 1986 a 2001, que servem de parâmetros para avaliação da eficácia das estratégias de posicionamento das firmas e da atratividade setorial, para os acionistas, dos principais setores da economia brasileira. Por meio da construção de cenários de negócios bidimensionais (bidimensional landscapes), constatou-se que os setores de Siderurgia, Eletroeletrônicos, Veículos e Têxtil apresentaram retornos negativos, e que nenhum dos setores analisados criou valor para os acionistas quando se considerou como custo de capital o custo de oportunidade do acionista. Os dados também sugerem que as firmas que atuam nos setores de Papel e Celulose, Energia, Bancos, Telecomunicações e Construção têm menores probabilidades, quando comparados com os demais setores estudados, de conseguirem retornos anormais por meio de suas estratégias.
\end{abstract}

Palavras-chaves: atratividade setorial; vantagem competitiva; economia brasileira.

\begin{abstract}
Fundamental issues dealt by scholars in the strategic field refer to the explanation of the heterogeneity of return distribution among firms. In Brazil, empirical researches that aim to measure abnormal returns and to relate them to strategic issues have not received proper attention by scholars. In this paper, empirical findings that serve both to measure industry attractiveness to stockholders and to assess the efficiency of positioning strategies are discussed. Following the foundations of the Industrial Organization Tradition, accounting archival data, covering 16 years (1986 - 2001) of main Brazilian economic sectors, were gathered and analyzed in a exploratory and longitudinal research design, in order to build two-dimensional business landscapes. Results suggest that Steel Manufacturing, Vehicle Manufacturing, Electronics Manufacturing and Textile industries have generated negative long-term average returns on equity (ROE) and that none of the analyzed industries, in the long-term average, have created value to their firms' stockholders, considering opportunity costs as the cost of capital. Also, firms in Paper and Cellulose, Energy, Financial, Telecommunications and Construction industries have lower probability, comparing to firms in other industries, to yield abnormal returns using positioning strategies in the industry.
\end{abstract}

Key words: industry attractiveness; competitive advantage; brazilian economy. 


\section{INTRODUÇÃO}

Freqüentes debates na literatura sobre estratégia competitiva visam a explicar por quais motivos certas firmas conseguem, ao longo do tempo, vantagens competitivas sobre seus concorrentes, o que resulta na geração de retornos superiores, significativamente maiores do que a média do setor no qual operam (Rumelt, Schendel e Teece, 1994).

No entanto nota-se, particularmente no Brasil, que pesquisas empíricas, que visam a mensurar e explicar o desempenho empresarial, não têm recebido a atenção devida. Isso se deve, em grande parte, à carência de bases de dados confiáveis que forneçam dados objetivos capazes de contemplar os setores produtivos de forma abrangente, e à existência de descontinuidades nas séries históricas, reflexo das rupturas econômicas do país nas últimas décadas (Fischmann e Zilber, 1999).

Como alternativa, pesquisas empíricas sobre estratégia empresarial têm-se utilizado de medidas subjetivas para avaliar o desempenho empresarial, ou de medidas combinadas, com indicadores objetivos e subjetivos (Perin e Sampaio, 1999; Marques e Moraes, 2001). Contudo problemas de ordem metodológica na definição operacional dos construtos relacionados à estratégia, como apontam Costa e Silva (2002), prejudicam as propriedades de generalização e de previsibilidade dos resultados.

Como conseqüência, a investigação do relacionamento estratégia-desempenho pode sofrer com problemas de validade científica, o que dificulta o desenvolvimento de estudos de cunho explanatório e a elaboração de prescrições. Talvez em função disso, a produção científica em estratégia no Brasil, na última década, caraterizou-se por estudos descritivos, principalmente sob a forma de estudos de caso (Bertero, Vasconcelos e Binder, 2003).

Com o intuito de incrementar a pesquisa empírica sobre estratégia competitiva no âmbito do contexto brasileiro, este estudo, de cunho exploratório, tem como objetivo construir indicadores objetivos que auxiliam na compreensão do relacionamento estratégia-desempenho. Assumem-se as hipóteses da tradição da Organização Industrial, para mensurar as variações do nível de atratividade intersetorial e da eficácia das estratégias competitivas, em diversos setores da economia brasileira ${ }^{(2)}$.

Como sugerido em estudo semelhante por Ghemawat (1999), foram construídos cenários de negócios bidimensionais (two-dimensional landscapes) que retratam 
o potencial de retorno econômico de cada um dos setores analisados. Os cenários construídos fornecem parâmetros para avaliação do nível de atratividade setorial e da eficácia das estratégias competitivas, do ponto de vista dos acionistas e futuros investidores. Como resultado, possiveis relacionamentos podem ser hipotetizados sobre a capacidade de geração de retornos superiores para os acionistas, ao longo dos setores investigados.

\section{Pressupostos Teóricos}

Explicações teóricas da heterogeneidade na distribuição dos retornos auferidos pelas firmas divergem quanto à ênfase dada aos fatores relacionados à indústria, ou setor, em que as firmas operam e aos fatores idiossincráticos das empresas. De um lado estão as perspectivas teóricas derivadas da Organização Industrial, inauguradas por Caves e Porter (1977) e Porter (1980), que enfatizam a influência das características estruturais do setor e, do outro, as perspectivas fundamentadas na posse e na utilização eficiente de recursos essenciais (Wernefelt, 1984; Barney, 1986, 2001; Dierickx e Cool, 1989; Peteraf, 1993). Estas, conforme explicam Vasconcelos e Cyrino (2000) e Mello e Cunha (2001), consideram que fatores específicos das firmas, e não do setor, explicam a realização de retornos superiores pelas empresas.

Pesquisas empíricas foram conduzidas para mensurar e testar os efeitos das condições setoriais e das firmas sobre o seu desempenho. Pode-se citar o trabalho seminal de Schmalensee (1985) que, em estudo cross-sectional, investigou os efeitos que as condições setoriais, as características corporativas do grupo controlador e a participação de mercado exerciam sobre a rentabilidade das unidades de negócios de corporações manufatureiras diversificadas.

Os resultados de Schmalensee (1985) sugerem que as características setoriais têm forte influência na rentabilidade média dos setores. Mais especificamente, as características setoriais explicam cerca de $75 \%$ da variação, sugerindo que indústria ou setor deve considerar-se como importante unidade de análise.

Schmalensee (1985) constatou, ainda, que cerca de 20\% da variação das rentabilidades das unidades estratégicas de negócios são explicadas pelas características setoriais em que atuam, apesar de ser quase a totalidade da variação explicada pelo seu modelo, o que corrobora a importância das diferenças setoriais. Porém, como lembra o autor, "é importante reconhecer que 80\% da variação na rentabilidade da unidade de negócios não estão relacionados com efeitos da indústria ou da sua participação de mercado. Enquanto as diferenças setoriais importam, elas não são tudo o que importam”. 
Outra constatação importante sugere que as características do grupo controlador não têm efeito sobre a rentabilidade de suas unidades estratégicas de negócio; ou seja, a rentabilidade obtida por uma corporação diversificada em um setor não explica a rentabilidade de outra unidade estratégica de negócio, do mesmo grupo, em outro setor escolhido aleatoriamente.

Rumelt (1991) deu prosseguimento às análises em estudo que utiliza uma série histórica de quatro anos, porém restrito ainda às unidades de negócios de corporações manufatureiras diversificadas. Ele considerou, além da participação de mercado analisada por Schmalensee (1985), variáveis adicionais para mensurar as características idiossincráticas das firmas. Rumelt (1991) constatou que as características da estrutura setorial explicavam somente de $9 \%$ a 16\% da variação das rentabilidades das unidades de negócios, contra cerca de $45 \%$ explicados pelas características específicas das firmas, tais como sua participação de mercado, heterogeneidade de ativos, diferenciação dos produtos e diferenças nos processos organizacionais.

Em estudo mais recente, McGahan e Porter (1997) retomaram o debate sobre a contribuição relativa das características estruturais do setor versus características específicas das firmas na explicação das variabilidade dos retornos. Utilizando métodos estatisticamente mais robustos do que seus antecessores, McGahan e Porter (1997) conduziram uma pesquisa com dados referentes a 14 anos, considerando as unidades estratégicas de negócio, de corporações diversificadas, em diferentes setores, excluindo-se o setor financeiro ${ }^{(3)}$. Seus resultados foram semelhantes aos de Schmalensee (1985), ao constatar que as condições setoriais têm influência significativa na explicação das rentabilidades das firmas, contribuindo com cerca de 19\% da sua variação.

Para McGahan e Porter (1997, as características da estrutura setorial são importantes e não devem ser desconsideradas - referindo-se às conclusões de Rumelt (1991) - principalmente por causa dos seguintes motivos:

a) os $19 \%$ da explicação da variação total das rentabilidades das unidades estratégicas de negócios, referentes às características setoriais, correspondem a 36\% da variação explicada pelo modelo utilizado;

b) as características no nível da indústria são intervenientes na relação entre as características do grupo controlador e a rentabilidade de suas unidades estratégicas de negócios;

c) os efeitos relativos das características setoriais do grupo controlador e das características específicas das firmas variam significativamente entre os diversos setores estudados, o que sugere a influência do contexto estrutural do setor; 
d) os efeitos relativos das características estruturais do setor tendem a ser mais estáveis do que as características específicas das firmas, mesmo com a existência de choques e ciclos econômicos (esta última constatação é particularmente importante para o contexto brasileiro).

Finalmente, McGahan e Porter (1997) não desconsideram os efeitos dos fatores específicos das firmas na explicação da distribuição heterogênea dos retornos, porém os autores alertam que seria incorreto desconsiderar os efeitos que as características estruturais dos setores exercem nas rentabilidades das firmas ${ }^{(4)}$. Na próxima seção, apresentam-se os principais pressupostos das perspectivas teóricas derivadas da Organização Industrial.

\section{A Tradição da Organização Industrial}

Conforme McGahan e Porter (1997), a tradição da Organização Industrial compreende as perspectivas teóricas sobre vantagem competitiva que derivam de Caves e Porter (1977), Porter (1980) e, posteriormente, de Oster (1990). Apesar de muito utilizada em trabalhos acadêmicos nas últimas décadas, faz-se necessário uma sucinta descrição de sua origem e de seus pressupostos.

A Organização Industrial baseia-se na tricotomia estrutura-comportamentodesempenho, proposta inicialmente por Mason $(1939,1949)$ e desenvolvida por Bain (1959); isto é, o desempenho das firmas é determinado pelo comportamento - ou conduta estratégica de compradores e vendedores - e este é determinado pela estrutura da indústria na qual as firmas atuam. A Figura 1 lista as principais variáveis do modelo da Organização Industrial.

\section{Figura 1: Modelo de Análise da Organização Industrial}

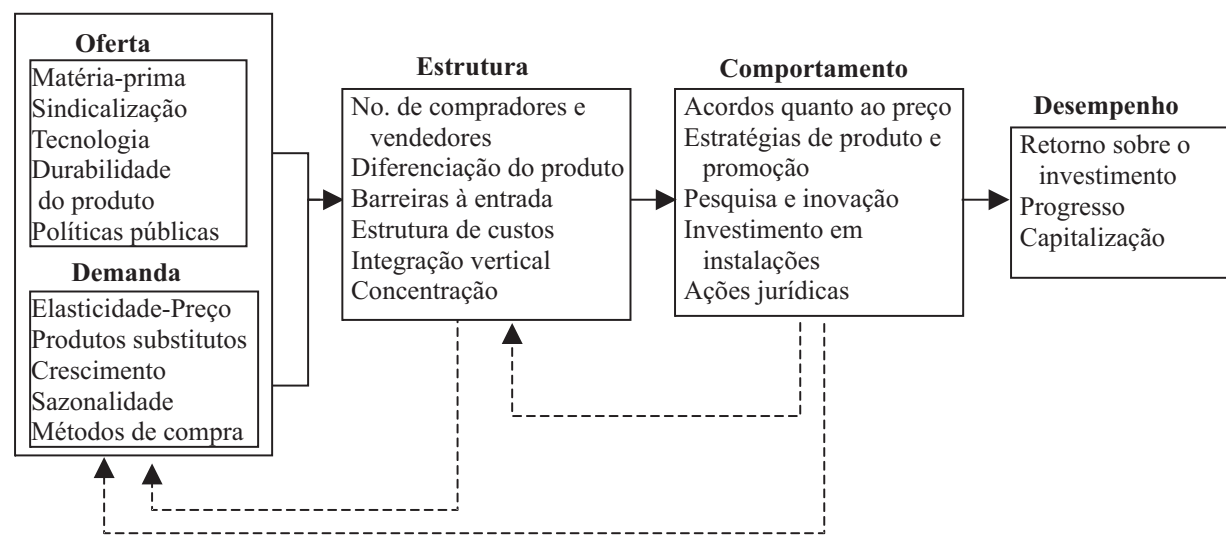

Fonte: adaptado de Scherer e Ross (1980). 
Em linhas gerais, o desempenho das firmas é determinado pelo comportamento dos concorrentes existentes, os quais moldam conjecturas sobre os movimentos competitivos tanto dos atuais participantes como dos possíveis entrantes na indústria. Por exemplo, iniciativas de investimentos não-recuperáveis, lealdade dos consumidores a produtos diferenciados e necessidade de acesso privilegiado a recursos ajudam a erguer barreiras de entrada, as quais podem ser consideradas tanto de natureza estrutural como endógena (Caves e Porter, 1977).

Caves e Porter (1977) especificaram o conceito de barreiras de entrada para o conceito de barreiras de mobilidade entre grupos de uma indústria, as quais atenuam a imitação por parte dos competidores e, em conseqüência, criam monopólios temporários e retornos superiores. Porter (1980) popularizou a utilização, no campo da estratégia competitiva, da tricotomia estruturacomportamento-desempenho, tanto no meio acadêmico como profissional, por meio do modelo das Forças Competitivas e das suas definições de estratégias genéricas de posicionamento (liderança no custo ou diferenciação). Para o autor, forças competitivas originadas na estrutura da indústria pressionam as empresas no sentido de reduzir suas rentabilidades. Como defesa, as empresas devem posicionar-se na indústria, utilizando uma das estratégias genéricas, cuja implementação e comprometimento com sua efetivação inibem a imitação por parte dos concorrentes, criam barreiras de mobilidade e geram retornos superiores.

\section{Nível de Atratividade Setorial e Eficácia das Estratégias de Posicionamento}

Ghemawat (1999) sintetiza os pressupostos da tradição da Economia Industrial em duas dimensões, que se relacionam para explicar o desempenho das firmas: a) o nível de atratividade do setor no qual a firma atua; e b) as estratégias de posicionamento competitivo utilizadas pela firma. Enquanto a primeira dimensão se refere aos efeitos no nível do setor, a segunda aborda a forma de competição, utilizada pela firma, para gerar vantagem competitiva e retornos superiores, acima da média dos concorrentes do setor.

As duas dimensões sintetizadas por Ghemawat (1999) são utilizadas nesta pesquisa empírica. Elas foram operacionalizadas para gerar indicadores objetivos que contribuam na compreensão das variações no desempenho das firmas, ao longo de diversos setores da economia brasileira.

A primeira dimensão, nível de atratividade do setor, pode ser compreendida conforme o raciocínio exposto na seção anterior, segundo o qual o efeito da estrutura industrial na explicação das rentabilidades médias setoriais corresponde acerca de 75\% (Schmalensee, 1985) e na explicação da variação da distribuição dos retornos 
das firmas corresponde acerca de 20\% (Schmalensee, 1985; McGahan e Porter, 1997), sendo, ainda, interveniente e mediadora dos efeitos de outras variáveis explicativas sobre o desempenho das empresas (McGahan e Porter, 1997).

Portanto, como sugerido por Ghemawat (1999) e apoiado nos resultados de Schmalensee (1985) e McGahan e Porter (1997), a determinação da rentabilidade das firmas que atuam em um mesmo setor tem, como causa comum, a estrutura industrial e, como conseqüência, tem sentido considerar a indústria como unidade de análise e reduzir os desempenhos individuais intra-setoriais em uma média setorial obtida em uma análise histórica, a qual deve representar o nível de atratividade setorial (Ghemawat, 1999).

A segunda dimensão a ser considerada pelas firmas na busca de retornos superiores é a utilização de estratégias de posicionamento. Como proposto por Porter (1980), as estratégias de posicionamento visam a defender a empresa contra as forças competitivas originárias na estrutura industrial, para proporcionar vantagem competitiva e retornos superiores. Portanto esta dimensão também leva em consideração a restrição imposta pela estrutura setorial e seus efeitos na redução do pontencial de retorno das firmas, no sentido de nivelá-las pela média permitida pelo setor.

Dessa forma, mantendo-se outras variáveis constantes, define-se, nesta pesquisa, eficácia das estratégias de posicionamento como a probabilidade de geração de retornos superiores. O valor dessa probabilidade, medida pela variação das rentabilidades intra-setoriais, em torno da média setorial, fornece um parâmetro da extensão até a qual se consegue descolar da média setorial por meio de uma estratégia de posicionamento. Em setores cuja variação medida é alta, a eficácia de uma estratégia de posicionamento de sucesso, implementada por uma firma do setor, também é alta, pois a probabilidade de obtenção de retornos superiores é grande. Caso contrário, as estratégias de posicionamento não seriam tão eficazes, visto que a probabilidade de obtenção de retornos superiores seria pequena.

Isso posto, o nível de atratividade setorial e a eficácia das estratégias de posicionamento foram mensurados ao longo de diversos setores da economia brasileira, com o intuito de auxiliar na compreensão da relação estratégia-desempenho. As demais seções deste artigo mostram os resultados desta pesquisa empírica.

\section{MÉTOdO}

Doze dos principais setores da economia brasileira foram analisados em estudo 
de caráter exploratório, utilizando dados históricos. Foram coletados dados objetivos acerca da rentabilidade do capital próprio e do montante de capital investido nas firmas pelos acionistas, no período de 1986 a 2001 (16 anos), fornecidos pela base de dados do sistema Economática ${ }^{(5)}$.

\section{Seleção dos Setores e das Empresas}

De todos os setores da economia brasileira, relevantes para a economia do país, foram selecionados aqueles que possuíam maior disponibilidade de dados, no que se refere ao número de empresas de capital aberto e à série histórica disponível.

Optou-se por considerar, na amostra de cada setor, somente as empresas de capital aberto, devido à indisponibilidade, à inconsistência e à falta de confiabilidade de dados secundários das empresas de capital fechado, frutos da nãoobrigatoriedade da publicação de informações sobre elas.

A abrangência dos setores selecionados pode ser avaliada em função da participação de cada um na atividade econômica medida pelo Produto Interno Bruto (PIB), publicada pelo Instituto Brasileiro de Geografia e Estatística (IBGE).

Os dados para o ano de 2000 mostraram o seguinte: indústria (36,6\%), serviços (57\%) e agricultura (7,5\%). A decomposição das atividades industriais foi a seguinte: indústria de transformação (60,3\%), construção civil (26,8\%), serviços industriais de utilidade pública $(8,4 \%)$, extração de petróleo $(3,1 \%)$ e extrativa mineral $(1,4 \%)$. Dentre as atividades da indústria de transformação as que tiveram maior participação no PIB em 2000 foram: refino de petróleo e petroquímico, celulose, papel e papelão, minerais metálicos, siderurgia, veículos, madeira, têxtil, vestuário e calçados, beneficiamento de produtos de origem vegetal e indústria do fumo.

A classificação acima foi comparada, na medida do possível ${ }^{(6)}$, com a classificação setorial do Economática: agropecuária; alimentos e bebidas; bancos e finanças; comércio; construção; eletroeletrônico; fundos; minerais não-metálicos; mineração; máquinas industriais; papel e celulose; gás e petróleo; química; siderurgia e metalurgia; telecomunicações; têxtil; transportes e serviços; veículos e peças; e outros.

Como resultado, verificou-se que os setores classificados no Economática abrangem grande parcela da atividade econômica do país. Os setores selecionados para a pesquisa foram escolhidos com base no número de empresas de capital aberto listadas. Os setores não selecionados foram excluídos, devido ao número 
muito restrito de empresas participantes, como aquelas ligadas ao petróleo. Os setores selecionados estão listados no Quadro 1.

\section{Quadro 1: Setores Selecionados no Economática}

\begin{tabular}{|c|c|}
\hline Setor & $\begin{array}{c}\text { Denominação } \\
\text { no estudo }\end{array}$ \\
\hline Alimentos e Bebidas & Alimentos \\
\hline Bancos e Finanças & Bancos \\
\hline Veículos e peças & Veículos \\
\hline Têxtil & Têxtil \\
\hline Telecomunicações & Teles \\
\hline Siderurgia e Metalurgia & Siderurgia \\
\hline Química & Química \\
\hline Papel\&Celulose & Papel\&Celulose \\
\hline Máquinas industriais & MaqIndustriais \\
\hline Eletroeletrônico & Eletroeletrônicos \\
\hline Energia Elétrica & Energia \\
\hline Construção & Construção \\
\hline
\end{tabular}

É importante ressaltar que a classificação setorial do Economática foi preferida em detrimento de outras classificações, devido à disponibilidade de dados e à sua utilização por bancos de investimento e instituições financeiras.

\section{Variáveis Mensuradas e Tratamento dos Dados}

O objetivo desta pesquisa é fornecer parâmetros para avaliação, do ponto de vista do acionista ou investidor, do nível de atratividade setorial e da eficácia das estratégias de posicionamento. Fundamentado nos pressupostos teóricos expostos na seção anterior, foram definidos os seguintes parâmetros setoriais.

\section{Quadro 2: Parâmetros Calculados no Estudo}

\begin{tabular}{|c|l|}
\hline Parâmetros & \multicolumn{1}{c|}{ Significado } \\
\hline ROE & $\begin{array}{l}\text { É a rentabilidade média sobre o capital próprio, obtida pelas firmas do setor, } \\
\text { em longo prazo. Expressa o nível de atratividade setorial. }\end{array}$ \\
\hline Desv Pad ROE & $\begin{array}{l}\text { Expressa a variação do ROE de cada setor em torno da média setorial. } \\
\text { Representa a probabilidade de obter retornos superiores, "descolados" da } \\
\text { média, por meio das estratégias de posicionamento competitivo. }\end{array}$ \\
\hline PL & $\begin{array}{l}\text { É o montante de capital médio investido pelos acionistas nas empresas do } \\
\text { setor, em longo prazo. Expresso em dólares americanos. }\end{array}$ \\
\hline ROE - $\mathrm{K}_{\mathrm{e}}$ & $\begin{array}{l}\text { É o potencial de rentabilidade permitido pelo setor, descontado o custo de } \\
\text { oportunidade dos acionistas. Expressa o retorno econômico do acionista, ou } \\
\text { seja, a criação, ou destruição, de valor. }\end{array}$ \\
\hline
\end{tabular}


Nesta pesquisa, considerou-se a abordagem de Ghemawat (1999), que considera o retorno econômico (ROE-Ke) como uma medida da atratividade industrial para o acionista. $\mathrm{O} \mathrm{K}_{\mathrm{e}}$ representa o custo de capital próprio, considerado, usualmente, como o custo de oportunidade dos acionistas. Dessa forma, considerou-se como custo de oportunidade para cada ano t, a taxa anual do Certificado de Depósito Interbancário (CDI), um dos papéis de menor risco no mercado. Considerou-se essa variável como custo de oportunidade para os acionistas, pois seria uma das opções de menor retorno em que o investidor poderia aplicar seus recursos, caso não tivesse investido na empresa.

O capital investido pelos acionistas, medido pelo patrimônio líquido, também foi sugerido por Ghemawat (1999), para auxiliar na construção dos cenários de negócios. Contudo não foi considerado, nesta pesquisa, a composição da estrutura de capital das empresas e seu índice de alavancagem, restringindo-se somente ao ponto de vista do acionista e futuros investidores. Não obstante, os efeitos do endividamento com capital de terceiros está captado no cálculo da rentabilidade para o acionista (ROE) de cada firma.

Para calcular os parâmetros definidos no Quadro 2, foram coletadas, no sistema Economática, as variáveis $\mathrm{ROE}_{\mathrm{it}}$ e $\mathrm{PL}_{\mathrm{it}}$, de cada firma i do setor analisado, para cada ano t do período considerado no estudo. Para calcular a variável denominada Retorno Econômico $\left(\right.$ ROE- $\left.\mathrm{K}_{\mathrm{e}}\right)$, foi necessária a coleta da taxa do CDI anual para cada ano t, que representou o custo de oportunidade $\left(\mathrm{Ke}_{\mathrm{t}}\right)$ para o acionista. Todos os parâmetros devem ser considerados como de longo prazo, com t variando de 1986 até 2001, exceto para $\mathrm{Ke}_{\mathrm{t}} \mathrm{e}$, conseqüentemente, ROE- $\mathrm{K}_{\mathrm{e}}$, cujos dados foram coletados para t a partir de 1996, por se constituir de um período mais estável para a utilização do CDI. O Quadro 3 mostra o tratamento realizado nos dados com a finalidade de calcular os parâmetros pretendidos. 


\section{Quadro 3: Procedimentos de Tratamento dos Dados}

\begin{tabular}{|c|c|c|}
\hline Etapas & Objetivo & Método \\
\hline Coleta do $\mathrm{ROE}_{\mathrm{it}}$ & Montar a base dados brutos. & $\begin{array}{l}\text { Coletou-se o ROE de cada empresa i, em } \\
\text { cada ano t, para cada setor analisado. }\end{array}$ \\
\hline Cálculo do $\mathrm{ROE}_{\mathrm{t}}$ & $\begin{array}{l}\text { Calcular a média do retorno do } \\
\text { acionista para cada ano t. }\end{array}$ & $\begin{array}{l}\mathrm{O} \mathrm{ROE}_{\mathrm{t}} \text { foi calculado a partir da média } \\
\text { dos ROE } \\
\text { it, para cada ano t. }\end{array}$ \\
\hline $\begin{array}{l}\text { Tratamento dos } \\
\text { outliers }\end{array}$ & $\begin{array}{l}\text { Retirar da amostra os valores } \\
\text { considerados discrepantes, fora dos } \\
\text { limites estabelecidos como normais, } \\
\text { para cada ano t. }\end{array}$ & $\begin{array}{l}\text { Para cada ano } t \text {, foram calculados os } \\
\text { limites superiores e inferiores iguais a, } \\
\text { respectivamente, mais ou menos dois } \\
\text { desvios-padrão da média } \text { ROE }_{t}\end{array}$ \\
\hline Cálculo do $\mathrm{ROE}_{\mathrm{i}}$ & $\begin{array}{l}\text { Estabelecer o retorno médio para o } \\
\text { acionista, realizado por cada empresa } \\
\text { i, ao longo do período analisado. }\end{array}$ & $\begin{array}{l}\text { Calculado partir da média dos } \mathrm{ROE}_{\mathrm{it}} \text { de } \\
\text { cada firma i, utilizando sua série histórica. }\end{array}$ \\
\hline $\begin{array}{l}\text { Cálculo do } \\
\text { parâmetro ROE }\end{array}$ & Calcular o parâmetro setorial ROE. & $\begin{array}{l}\text { Calculado a partir da média dos } \mathrm{ROE}_{\mathrm{i}} \text { de } \\
\text { cada empresa do setor. }\end{array}$ \\
\hline $\begin{array}{l}\text { Cálculo do } \\
\text { Desv Pad ROE }\end{array}$ & $\begin{array}{l}\text { Calcular o parâmetro setorial Desv } \\
\text { Pad ROE. }\end{array}$ & $\begin{array}{l}\text { Expressa a variação, calculada pelo } \\
\text { desvio-padrão dos } \mathrm{ROE}_{\mathrm{i}} \text { de cada empresa } \\
\text { do setor, em torno da média ROE. }\end{array}$ \\
\hline Coleta do $\mathrm{Ke}_{\mathrm{t}}$ & $\begin{array}{l}\text { Obter um indicador de custo de } \\
\text { oportunidade para os acionistas. }\end{array}$ & $\begin{array}{l}\text { Coletou-se a taxa anual do CDI para cada } \\
\text { ano t, a partir de } 1996 .\end{array}$ \\
\hline $\begin{array}{l}\text { Cálculo de } \\
\mathrm{ROE}_{\mathrm{it}}-\mathrm{Ke}_{\mathrm{t}}\end{array}$ & $\begin{array}{l}\text { Calcular o retorno econômico de cada } \\
\text { firma i, para cada período t. }\end{array}$ & $\begin{array}{l}\text { Calculado pela diferença entre o } \mathrm{ROE}_{\mathrm{it}} \mathrm{e} \\
\mathrm{Ke}_{\mathrm{t}} \text {, para t a partir de } 1996 .\end{array}$ \\
\hline $\begin{array}{l}\text { Cálculo de } \\
(\mathrm{ROE}-\mathrm{KE})_{\mathrm{i}}\end{array}$ & $\begin{array}{l}\text { Calcular o retorno econômico médio } \\
\text { gerado por cada empresa, ao longo } \\
\text { período analisado. }\end{array}$ & $\begin{array}{l}\text { Calculado pela média de } \mathrm{ROE}_{\mathrm{it}}-\mathrm{Ke}_{\mathrm{t}} \text {, para } \\
\text { cada empresa i, ao longo da série histórica } \\
\text { a partir de } 1996 \text {. }\end{array}$ \\
\hline $\begin{array}{l}\text { Cálculo do } \\
\text { Parâmetro } \\
\text { ROE-KE }\end{array}$ & $\begin{array}{l}\text { Calcular o parâmetro setorial ROE- } \\
\text { KE. }\end{array}$ & $\begin{array}{l}\text { Calculado pela média de }(\mathrm{ROE}-\mathrm{KE})_{\mathrm{i}} \text {, de } \\
\text { cada empresa do setor. }\end{array}$ \\
\hline
\end{tabular}

As seis primeiras etapas descritas no Quadro 3 foram repetidas para o cálculo do parâmetro PL, a partir das seguintes variáveis: patrimônio líquido de cada empresa i para cada período $\mathrm{t}\left(\mathrm{PL}_{\mathrm{it}}\right)$; patrimônio líquido médio do setor para cada ano t ( $\left(\mathrm{L}_{\mathrm{t}}\right)$; patrimônio líquido médio de cada empresa i ao longo do período estudado ( $\mathrm{PL}_{\mathrm{i}}$ ); e, finalmente, o PL setorial calculado pela média dos $\mathrm{PL}_{\mathrm{i}}$ de cada empresa do setor. Também foi calculado o parâmetro setorial PL96 pela média dos $\mathrm{PL}_{\mathrm{i}}$ de cada empresa $\mathrm{i}$, considerando somente os $\mathrm{PL}_{\mathrm{it}}$, para t maior ou igual a 1996, visando alinhar-se temporalmente com o parâmetro ROE-KE.

A utilização de uma série histórica de 16 anos possibilitou que situações específicas de cada ano fossem suavizadas pela média, conforme sugerido por Ghemawat (1999). E, para atenuar possíveis anormalidades, foi feito tratamento univariado para seleção de outliers, para cada ano t, como indicado no Quadro 3.

Optou-se por excluir os outliers ano-a-ano, tendo como referência a média setorial, para que o desempenho de uma determinada empresa em ano atípico não exerça influência sobre os parâmentros setoriais. Hair et al. (1998) sugerem a utilização de 2,5 devios-padrão, ou superior, no caso de amostras de tamanho acima de 80 observações. Nesta pesquisa, devido ao reduzido tamanho das 
amostras em alguns setores, às mudanças drásticas no ambiente ao longo do período pesquisado e à utilização de uma medida de variabilidade (Desv Pad ROE) como um dos principais parâmetros de análise, foi utilizado o critério de dois desvios-padrão para seleção dos outliers.

No cálculo do PL e do PL96, apesar de ter sido deflacionado em dólares americanos, não foi feito ajuste para a variação de preços em dólar. Porém ressalta-se que esse procedimento não invalida os principais resultados do trabalho.

\section{Resultados}

A Tabela 1 mostra o tamanho da amostra utilizada para cálculo dos parâmetros setoriais. Por exemplo, no setor Alimentos, foram consideradas 21 empresas para cálculo do parâmetro ROE-Ke, 22 para cálculo do ROE, 21 para cálculo do PL96 e 22 para cálculo do PL. A diferença entre os valores de n é devido à disponibilidade dos dados para as variáveis originais específicas de cada parâmetro. Outro valor importante é a média de $\mathrm{n}_{\mathrm{i}}$ - tamanho médio da série histórica disponível sobre cada empresa i - utilizada para calcular os parâmetros setoriais. Por exemplo, as empresas do setor Bancos forneceram, em média, uma série histórica de 10,5 anos de $\mathrm{ROE}_{\mathrm{it}}$ utilizados para o cálculo de seu ROE $_{\mathrm{i}}$. O ROE-Ke e o PL96 possuem menores médias de $n_{\mathrm{i}}$, pois foram considerados somente valores para t a partir de 1996. O valor de 4,20 anos para as Teles justifica-se pela recente criação dessas empresas com o processo de privatização.

Tabela 1: Tamanho das Amostras Utilizadas no Cálculo dos Parâmetros

\begin{tabular}{l|cc|cc|c|c|cc}
\hline \multirow{2}{*}{\multicolumn{1}{c}{ Setores }} & \multicolumn{2}{c|}{ ROE $-\mathbf{K}_{\mathbf{e}}$} & \multicolumn{2}{c|}{ ROE } & \multicolumn{2}{c|}{ PL96 } & \multicolumn{2}{c}{ PL } \\
\cline { 2 - 9 } & $\mathrm{N}$ & Média $_{\mathrm{n}}$ & $\mathrm{n}$ & Média $\mathrm{n}_{\mathrm{i}}$ & $\mathrm{N}$ & Média $\mathrm{n}_{\mathrm{i}}$ & $\mathrm{n}$ & Média $_{\mathrm{i}}$ \\
\hline Alimentos & 21 & 4,38 & 22 & 10,32 & 21 & 4,95 & 22 & 11,09 \\
Bancos & 18 & 4,50 & 18 & 10,50 & 21 & 5,29 & 21 & 11,19 \\
Vé́culos & 20 & 4,50 & 20 & 11,10 & 20 & 4,70 & 20 & 11,80 \\
Têxtil & 29 & 4,24 & 29 & 10,38 & 26 & 5,27 & 26 & 11,88 \\
Teles & 46 & 3,41 & 46 & 4,20 & 50 & 3,58 & 50 & 4,28 \\
Siderurgia & 35 & 4,74 & 35 & 12,31 & 33 & 4,94 & 35 & 12,34 \\
Química & 32 & 5,13 & 32 & 11,81 & 31 & 5,26 & 31 & 12,19 \\
Papel\&Celulose & 9 & 5,11 & 9 & 12,67 & 9 & 5,44 & 9 & 13,56 \\
MaqIndustriais & 13 & 4,54 & 14 & 11,43 & 14 & 5,07 & 14 & 13,79 \\
Eletroeletrônicos & 15 & 3,93 & 15 & 10,07 & 14 & 4,64 & 14 & 11,57 \\
Energia & 32 & 3,88 & 32 & 6,28 & 34 & 4,41 & 34 & 7,18 \\
Construção & 12 & 3,92 & 13 & 6,85 & 12 & 4,42 & 12 & 7,83 \\
\hline
\end{tabular}


De modo geral, na média de todos os setores analisados, o tamanho da série histórica para cálculo do ROE foi de 9,8 anos. É considerado índice significativo, quando comparado com o estudo de McGahan e Porter (1997), que obteve uma média de 5,7 anos, e com o estudo de Rumelt (1991), que obteve 4 anos.

As distribuições intra-setoriais dos $\mathrm{ROE}_{\mathrm{i}}$, em função do tratamento estatístico dos outliers, tiveram suas assimetrias atenuadas. Isso resultou, considerando o conjunto de 12 setores, um índice de assimetria mediano de $\mathrm{ROE}_{\mathrm{i}}$ de $-0,67$ e um índice de assimetria médio de -0,92 (principalmente devido ao setor Têxtil, que apresentou índice de assimetria -2,1, discrepante dos demais setores).

Os valores dos parâmetros setoriais calculados estão expostos na Tabela 2, classificados por ordem ascendente do ROE.

Tabela 2: Parâmetros Setoriais Calculados

\begin{tabular}{c|c|cc|cc}
\hline \multirow{2}{*}{ SETORES } & ROE-KE & \multicolumn{2}{|c|}{ ROE (\%) } & \multirow{2}{*}{ PL (US\$) } & \multirow{2}{*}{ PL96 (US\$) } \\
\cline { 3 - 4 } & $\mathbf{( \% )}$ & Média & Desv Pad & & \\
\hline Siderurgia & $-41,44$ & $-7,82$ & 16,14 & $301.813,02$ & $244.512,20$ \\
Eletroeletrônico & $-33,09$ & $-4,14$ & 21,40 & $104.579,83$ & $155.840,46$ \\
Veículos & $-33,34$ & $-3,65$ & 17,68 & $58.883,82$ & $51.986,18$ \\
Têxtil & $-30,76$ & $-2,07$ & 13,80 & $82.451,38$ & $82.696,69$ \\
Química & $-27,21$ & 0,14 & 16,05 & $235.838,40$ & $256.421,66$ \\
Energia & $-22,53$ & 0,57 & 3,87 & $1.180 .564,88$ & $1.285 .347,05$ \\
Alimentos & $-25,21$ & 2,26 & 8,99 & $125.442,04$ & $160.013,89$ \\
Maqindustriais & $-21,97$ & 2,73 & 8,99 & $79.978,17$ & $87.185,02$ \\
Papel\&Celulose & $-21,93$ & 3,38 & 2,65 & $608.533,05$ & $750.521,35$ \\
Construção & $-19,40$ & 4,08 & 5,94 & $54.345,49$ & $54.272,18$ \\
Teles & $-13,88$ & 7,49 & 5,81 & $784.526,01$ & $882.115,43$ \\
Bancos & $-12,71$ & 11,74 & 5,09 & $1.042 .100,71$ & $1.373 .566,07$ \\
\hline
\end{tabular}

A partir dos dados da Tabela 2, pode-se construir cenários de negócios (twodimensional landscape), como sugerido por Ghemawat (1999), utilizando o ROE e o PL das empresas de capital aberto para cada setor, de forma comparativa, como ilustrado no Gráfico 1 . O cenário de negócios ajuda a visualizar a extensão até a qual a rentabilidade média para o acionista difere através dos setores, ao longo de períodos prolongados; em outras palavras, mostra como a componente comum da rentabilidade varia sistematicamente ao longo dos setores (Ghemawat, 1999). O cenário foi elaborado de forma que a altura da caixa represente o retorno médio, positivo ou negativo, para o acionista, e a sua largura seja diretamente proporcional ao montante médio de capital investido pelos acionistas (PL). 


\section{Gráfico 1: Cenário de Negócios ROE x PL}

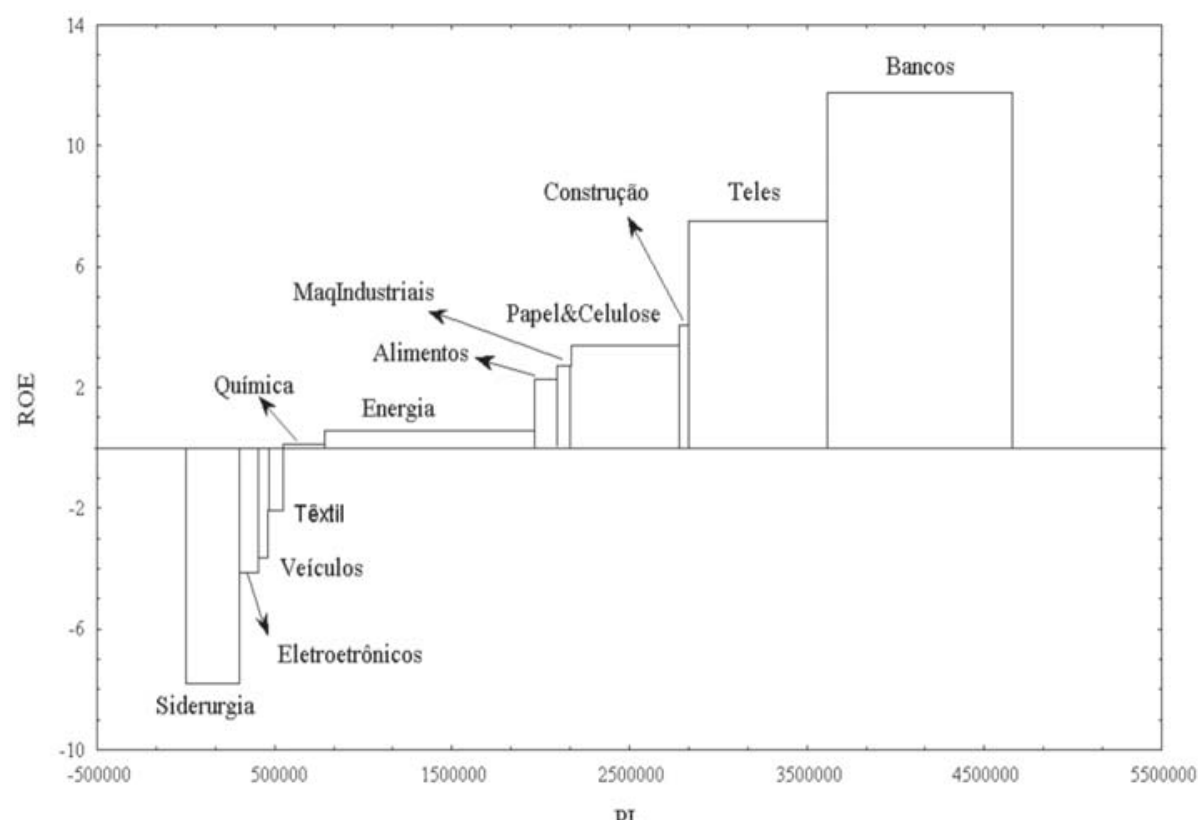

Pode-se constatar que, enquanto os setores Têxtil, Veículos, Eletroeletrônicos e Siderurgia apresentam ROE menores do que zero, os demais apresentam retornos médios positivos para os acionistas. Isso significa que, na média dos últimos 16 anos, cerca de $12 \%$ do capital investido nas empresas de capital aberto, pertencentes aos setores analisados, foram alocados em setores com rentabilidade negativa para os acionistas.

O setor Bancos apresentou o melhor desempenho; porém tal desempenho pode ser explicada pelo alto nível de alavancagem de suas firmas. Em geral, pesquisas empíricas setoriais excluem esse setor da análise em função de suas características diferenciadas dos demais, principalmente no tocante ao uso de capital de terceiros.

Não se pretende, aqui, tecer considerações sobre cada setor, pois fugiria ao escopo desta pesquisa. Isso deve ser feito por meio de análise detalhada da estrutura industrial, do comportamento das firmas e do mercado do setor. Não obstante, pode-se notar que a estrutura oligopolista do setor Teles promoveu altos valores, relativos aos demais, para o ROE.

Em geral, a amplitude do ROE entre os setores foi cerca de 14 pontos percentuais, desconsiderando o setor Bancos. Retirando-se os extremos, Siderurgia, Teles e Bancos, essa amplitude cai para cerca de 3,3 pontos percentuais, os quais concentram, aproximadamente, $53 \%$ do capital investido. 
É uma amplitude significativa, quando comparada com estudos realizados na economia americana; eles constataram que cerca de pouco mais da metade dos investimentos foram feitos em setores que estão, no máximo, a dois pontos percentuais um do outro (Ghemawat, 1999).

Porém o alto custo de oportunidade reduziu drasticamente o retorno econômico para os acionistas em todos os setores, como mostra o Gráfico 2. Pode-se observar, nesse cenário de negócios, que nenhum dos setores analisados apresentou retornos médios que compensassem o custo de oportunidade dos acionistas (isto é, a rentabilidade anual do CDI). Isso significa que, na média, os investimentos feitos em empresas de capital aberto dos setores amostrados, nos últimos seis anos (1996 a 2001), não criaram valor para seus acionistas.

\section{Gráfico 2: Destruição de Valor para o Acionista através dos Setores (ROE-K) x PL96}

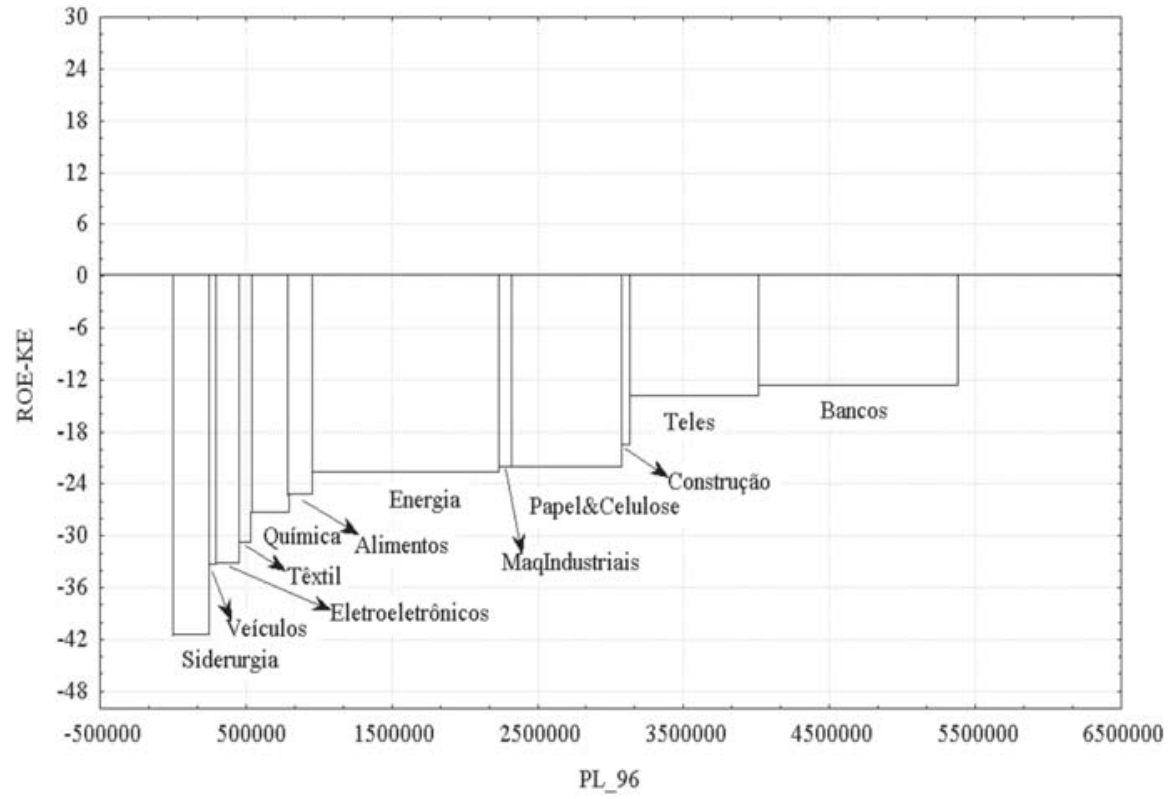

As altas taxas de juros do mercado brasileiro, e seu uso como instrumento de política monetária, faz com que dificilmente investidores obtenham retornos, investindo no setor produtivo do país, que se sobreponham à rentabilidade do mercado financeiro. As taxas de juros praticadas em patamares elevados e a escassez de recursos para financiamentos em longo prazo tendem a inibir a captação de recursos de terceiros pelas empresas( ${ }^{(7)}$; e, aquelas que se aventuram nesta direção tendem a ter seu desempenho econômico comprometido, porque, como foi evidenciado, o retorno permitido pelos setores não se sobrepõe à rentabilidade de um dos títulos mais seguros do mercado, o CDI. 
Contudo pode-se questionar se a taxa de juros é o único interveniente. Nos resultados, observa-se que mesmo que a taxa Selic atingisse patamares de países desenvolvidos, em torno de $7 \%$ ao ano, poucos setores conseguiriam um resultado satisfatório, do ponto de vista de retorno econômico para o acionista.

Além das rentabilidades médias e dos retornos econômicos médios permitidos para cada setor, o outro parâmetro calculado foi a variação medida das rentabilidades $\mathrm{ROE}_{\mathrm{i}}$ das firmas em torno da média ROE do setor. Esse parâmetro foi denominado de Desv Pad ROE e seus valores setoriais estão expostos no Gráfico 3. Quanto maior seu valor, maior a probabilidade de se obterem retornos superiores, e melhor a eficácia de estratégias de posicionamento de sucesso. Por outro lado, quanto menor o Desv Pad ROE, menor a eficácia das estratégias de posicionamento, visto que diminui a probabilidade de uma firma obter retornos superiores.

\section{Gráfico 3: Medida da eficácia das estratégias de posicionamento (Desv Pad ROE)}

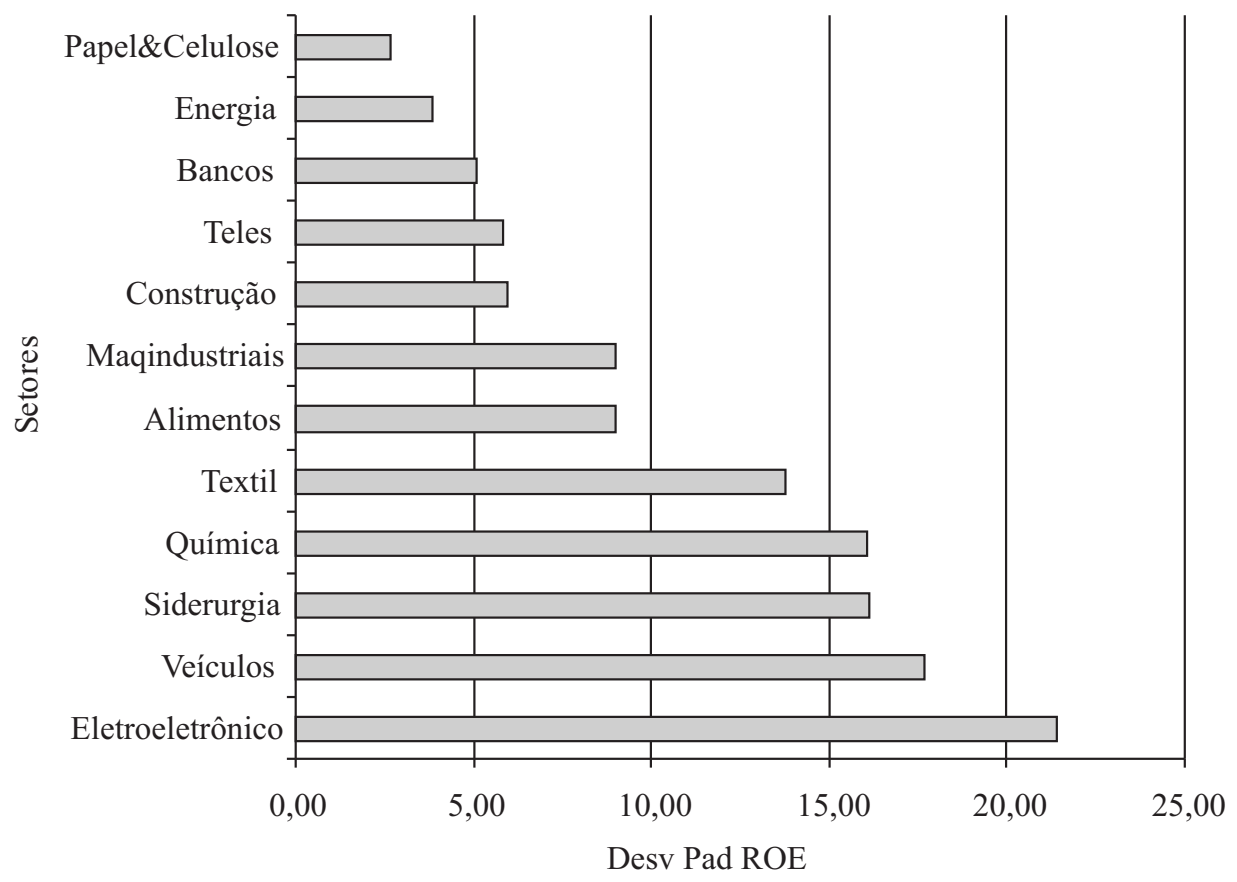

No Gráfico 3, pode-se extrair de forma visual e qualitativa, a título de formulação hipotética, dois grupos de setores, classificados arbritrariamente, que são antagônicos do ponto de vista da eficácia das estratégias de posicionamento. O primeiro grupo inclui as firmas dos setores com menor Desv Pad ROE: 
Papel\&Celulose, Energia, Bancos, Teles e Construção. Por outro lado, no segundo grupo, os setores Química, Siderurgia, Veículos e Eletroeletrônico apresentam os maiores valores para Desv Pad ROE.

A Tabela 3 apresenta as probabilidades de significância do teste de Levene (Milliken e Johnson, 1984) para a homogeneidade das variâncias. As células assinaladas com asterisco são significativas para um nível de significância de $5 \%$. Pode-se notar que os setores que formam os dois grupos descritos acima não apresentam diferenças significativas entre si, para suas variâncias do ROE conforme assinalados pelos dois triângulos sobre a tabela. Por outro lado, todos os outros relacionamentos possíveis entre os setores integrantes dos dois grupos apresentam diferenças significativas, para os níveis usuais de significância.

Tabela 3: Probabilidades de Significância para o Teste de Levene

\begin{tabular}{|c|c|c|c|c|c|c|c|c|c|}
\hline Setores & Grupo & P\&C & Energia & Teles & Constr & Quimica & Siderurg & Veículos & Eletro \\
\hline Bancos & 1 & 0,0620 & 0,1230 & 0,9006 & 0,9528 & $0,0055^{*}$ & $0,0000^{*}$ & $0,0001^{*}$ & $0,0033^{*}$ \\
\hline$P \& C$ & & & 0,4036 & 0,1172 & 0,2048 & $0,0121^{*}$ & $0,0002^{*}$ & $0,0008^{*}$ & 0,0139 * \\
\hline Energia & 1 & & & 0,0884 & 0,2620 & $0,0000^{*}$ & $0,0000^{*}$ & $0,0000^{*}$ & $0,0000^{*}$ \\
\hline Teles & 1 & & & & 0,8715 & $0,0000^{*}$ & $0,0000^{*}$ & $0,0001^{*}$ & $0,0000^{*}$ \\
\hline Constr & 1 & & & & & $0,0177^{*}$ & $0,0002^{*}$ & $0,0001^{*}$ & $0,0129^{*}$ \\
\hline Quimica & 2 & & & & & & 0,4033 & 0,3555 & 0,3585 \\
\hline Siderurg & 2 & & & & & & & 0,7502 & 0,6371 \\
\hline Veículos & 2 & & & & & & & & 0,8558 \\
\hline Eletro & 2 & & & & & & & & \\
\hline
\end{tabular}

Sem entrar no mérito da análise estrutural e da concorrência de cada setor, pode-se conjecturar, desconsiderando-se o setor Bancos, que o setor de Energia e Teles têm baixos valores para Desv Pad ROE por serem altamente regulamentados pelo Governo. Já o setor de construção possui um grupo de fornecedores oligopolizados e poderosos, o que se reflete na baixa variação medida para o ROE. Interpretando essas considerações à luz da tradição da Organização Industrial, as características estruturais desses setores tornam as estratégias de posicionamento competitivo de suas firmas pouco eficazes, pois a probabilidade de uma firma obter retornos superiores é baixa (pelo menos quando comparada com os demais setores).

Por outro lado, os setores de Veículos e Eletroeletrônicos, do grupo 2, apresentaram as maiores variações em torno das suas rentabilidades médias. Isso significa que a estrutura desses setores possibilita a existência, com maior probabilidade do que os demais setores, de firmas que conseguem retornos superiores, utilizando uma estratégia de posicionamento de sucesso; ou seja, nesse caso, a eficácia das estratégias de posicionamento é alta. 


\section{Conclusões}

Este trabalho apresentou os resultados de pesquisa empírica para determinar parâmetros úteis nas avaliações do nível de atratividade setorial e da eficácia das estratégias de posicionamento, ao longo de diversos setores da economia brasileira.

Fundamentando-se na tradição da Organização Industrial (Porter, 1980; Ghemawat, 1999), foi conduzido um estudo exploratório, baseado em dados objetivos de uma série histórica de 16 anos. Foram coletados dados referentes às rentabilidades sobre o capital próprio (ROE) de cada empresa de capital aberto, no período compreendido entre 1986 e 2001, ao longo de 12 setores selecionados para o estudo. Os dados foram devidamente tratados para que pudessem ser calculados parâmetros setoriais: a rentabilidade média do setor (ROE), o montante médio de capital próprio investido em cada firma do setor (PL), o retorno econômico médio setorial para o acionista (ROE-KE).

Os cenários de negócios (two-dimensional landscapes), como sugeridos por Ghemawat (1999), foram construídos a partir dos parâmetros setoriais e sugerem diferenças ao longo dos setores, quanto às rentabilidades médias do acionista e à probabilidade de obtenção de retornos superiores.

Dentre os principais resultados, observa-se que 11\% do capital próprio das firmas amostradas foram investidos em operações que realizaram retornos negativos em longo prazo. Descontando-se o custo de oportunidade, nenhum dos 12 setores analisados gerou valor para os acionistas, pois todos apresentaram retornos econômicos médios negativos. Mais da metade dos investimentos feitos por acionistas foram alocados em setores industriais com amplitude de 3,3\% de suas rentabilidades médias (desconsiderando-se setores extremos como Bancos, Teles e Siderurgia). Comparada com outros estudos (Ghemawat, 1999) é uma amplitude considerável e reforça as idéias da tradição da Organização Industrial ${ }^{(8)}$.

Importa ressaltar a importância do parâmetro Desv Pad ROE como medida da eficácia das estratégias de posicionamento e, consequentemente, da atuação gerencial. Considerando-se os dois grupos antagônicos formados pelos setores analisados, e apresentados na Tabela 3, pode-se formular a hipótese de que um gerente competente, que atua em setor do segundo grupo, não teria o mesmo valor atuando em setor do primeiro grupo, visto que sua intervenção na formulação e implementação de estratégias de sucesso não teria a mesma eficácia, na medida em que o setor permite baixa probabilidade de uma firma obter retornos superiores. 
Finalmente, é importante que se exponham algumas limitações. A primeira limitação refere-se à análise do risco. Não foi pretensão deste trabalho avaliar o risco para o acionista, inerente a cada setor, não obstante o parâmetro Desv Pad ROE possa ser utilizado para esse fim. O parâmetro referente à medida da variação dos retornos intra-setoriais, neste estudo, reflete a eficácia das estratégias, partindo do pressuposto da existência de um gerente competente hipotético. Dessa forma, focaliza-se na probabilidade de obter retornos superiores, ou seja, de "descolar" da média setorial para cima e, não, na probabilidade de insucesso ${ }^{(9)}$.

A segunda limitação diz respeito aos dados disponíveis. A base de dados do Economática fornece dados objetivos somente para as empresas de capital aberto, o que restringe a amostra. Por outro lado, a utilização de dados objetivos acerca de empresas de capital fechado, pode incorrer em erros, devido à sua falta de confiabilidade.

A terceira limitação refere-se aos procedimentos para exclusão dos outliers. Como dito anteriormente, esse tratamento estatístico é necessário para atenuar o efeito de valores extremos, atípicos em determinado ano, no cálculo dos parâmetros setoriais anuais. Contudo toda exclusão, apesar de seguir critérios aceitos, é arbitrária, e seus efeitos, em amostras pequenas, podem ser significativos. "Outliers não podem ser categorizadamente classificados como benéficos ou problemáticos, mas devem ser vistos dentro do contexto de análise e devem ser avaliados em função do tipo de informação que eles fornecem." (Hair et al., 1998, p. 64). Nesse sentido, em função das peculiaridades e das mudanças drásticas do contexto brasileiro ao longo do período estudado, o prejuízo da exclusão de valores considerados discrepantes parece ser menor do que o da sua permanência.

Já a quarta limitação relaciona-se com a identificação de melhores estratégias. Nesse sentido, deve-se deixar claro que este trabalho não pretendeu explorar a questão dos grupos estratégicos dentro dos setores, como feito, por exemplo, por Thomas e Venkatraman (1988), Smith et al. (1997) e, no Brasil, por Kalaf e Bomtempo (2000).

A última limitação refere-se às limitações da tradição da Organização Industrial. Como constatado por McGahan e Porter (1997), a estrutura industrial é realmente importante na explicação dos retornos das empresas e seus efeitos tendem a perdurar ao longo do tempo; contudo fatores específicos das firmas também exercem importantes efeitos na rentabilidade das empresas. Isso significa que a probabilidade de obter e manter retornos superiores depende não somente da estrutura setorial, mas de fatores idiossincráticos relacionados ao uso produtivo 
de recursos essenciais, tais como a capacidade gerencial (Mello e Cunha, 2001). Portanto o Desv Pad ROE consiste em um parâmetro para avaliar não somente a eficácia de estratégias de posicionamento, mas a extensão até a qual se pode conseguir eficiência superior na utilização de recursos essenciais.

Apesar dessas limitações, os parâmetros calculados fornecem base empírica, tanto para acadêmicos como para investidores e gestores. Futuros trabalhos podem explorar cada setor individualmente e identificar as razões que determinam sua rentabilidade média e a variação das rentabilidades intra-setoriais calculadas aqui; sejam razões relacionadas com as características estruturais ou com as características específicas das firmas.

Finalmente, os resultados apresentados neste trabalho podem ser utilizados por investidores na avaliação de novos negócios, como, por exemplo, firmas diversificadas que procuram novas alternativas de investimento, sejam firmas nacionais ou entrantes internacionais que queiram expandir seus negócios no país.

\title{
Notas
}

\begin{abstract}
${ }^{1}$ Uma versão anterior deste trabalho foi agraciada com o Prêmio ANPAD, na área de Estratégia em Organizações, por ocasião do ENANPAD 2002. Os autores de público reconhecem o auxílio financeiro e material, para a realização de parte desta pesquisa, provenientes do Programa de Bolsas de Iniciação Científica (PROBIC) da Universidade do Vale do Itajaí (UNIVALI).
\end{abstract}

${ }^{2}$ Vale a pena ressaltar que este estudo é de cunho exploratório e não tem como objetivo testar modelos de relacionamento entre variáveis. Muito menos visa testar as relações ou as hipóteses da tradição da Organização Industrial na explicação da vantagem competitiva das empresas que atuam no contexto brasileiro.

${ }^{3}$ A rentabilidade medida pelos autores não considerou o acionista, mas uma medida operacional resultante da razão entre Lucro Antes dos Juros e do Imposto e o Ativo Total.

${ }^{4}$ Day (1999) apresenta um modelo integrador no qual as perspectivas teóricas são complementares e não concorrentes na explicação da vantagem competitiva das firmas e a realização de retornos superiores ao longo do tempo. Já Hill e Deeds (1996) compartilham da idéias de que fatores de mercado determinam o desempenho, mas questionam o efeito causal da estrutura industrial.

${ }^{5} \mathrm{O}$ sistema Economática é formado por bases de dados com informações contábeis, financeiras e econômicas de empresas de capital aberto, listadas nas principais bolsas de valores da América Latina. A base de dados do sistema é alimentada periodicamente com informações publicadas pelas empresas e pelo mercado.

${ }^{6}$ Devido a divergências metodológicas, não foi possível identificar, com precisão, a participação relativa de cada setor classificado no Economática na atividade econômica do país, medida pelo PIB. 
${ }^{7}$ Pereira (2000) constatou que os níveis de alavancagem praticados no Brasil são muito inferiores aos praticados em economias mais estáveis.

${ }^{8}$ Como não é objetivo deste estudo validar os pressupostos da tradição da Organização Industrial, não foram realizados testes estatísticos para tal finalidade e as afirmações a esse respeito restringemse apenas ao seu caráter sugestivo.

${ }^{9}$ Pretende-se investigar, em trabalhos futuros, a correlação negativa e moderada que se verificou nos dados entre ROE e Desv Pad ROE, o que sugere uma relação não-usual entre risco e retorno.

\section{Artigo recebido em 08.11.2002. Aprovado em 21.11.2003.}

\section{REFERÊNCIAS}

BAIN, J.

Industrial organization. New York: Wiley, 1959.

\section{BARNEY, J.}

Strategic factor markets: expectations, luck and business strategy. Management Science, v. 42, p.1.231-1241, 1986.

\section{BARNEY.J.}

Is the Resource-Based "View" a useful perspective for strategic management research? Yes. Academy of Management Review, v. 26, n. 1, p.41-56, 2001.

BERTERO, C.;

VASCONCELOS, F.;

BINDER, $M$.

Estratégia empresarial: a produção científica brasileira entre 1991 e 2002.

Revista de Administração de Empresas, v. 43, n.4, p. 48-62, 2003.

CAVES, R.;

PORTER, $M$.

From entry barriers to mobility barriers: conjectural decisions and contrived deterrence to new competition. Quarterly Journal of Economics, v. 91, p. 241-261, 1977.

COSTA, L.;

SILVA, J.

As tipologias estratégicas "realmente existem”? In: ENCONTRO ANUAL DA ANPAD, 21., 2002, Salvador. Anais... Salvador: ANPAD,2002.

DAY, G

Manutenção da vantagem competitiva: criação e sustentação das vantagens competitivas em ambientes competitivos dinâmicos. In: DAY, G; REIBSTEIN, D. A dinâmica da estratégia competitiva. Rio de Janeiro: Campus, 1999.

\section{DIERICKX, I.;}

COOL, K.

Asset stock accumulation and sustainability of competitive advantage. Management Science, v. 33, n. 12, 1989. 
FISCHMANN, A.;

ZILBER, $M$.

Utilização de indicadores de desempenho como instrumento de suporte à gestão estratégica. In: ENCONTRO ANUAL DA ANUAL DAANPAD, 23., 2002, Foz do Iguaçu. Anais... Foz do Iguaçu: ANPAD, 1999.

GHEMAWAT, P.

Strategy and the business landscape. Addison Wesley Logman, 1999.

HAIR, J.;

ANDERSON, R. E.;

TATHAM, R. L.;

BLACK, W. C.

Multivariate data analysis. 5. ed. New Jersey: Prentice-Hall, 1998.

HILL, C.;

DEEDS, D.

The importance of industry structure for the determination of firm profitability: a new Austrian perspective. Journal of Management Studies, v.33, n.4, p.429-451, 1996.

KALAF, E.;

BOMTEMPO, J.

Grupos estratégicos, competição baseada em recursos e a operacionalização da estratégia. In: ENCONTRO ANUAL DA ANPAD, 24., 2000, Florianópolis. Anais... Florianópolis: ANPAD, 2000.

MARQUES, D.;

MORAES, W.

Desempenho competitivo, capacidades diferenciadoras e posicionamento competitivo. In: ENCONTRO ANUAL DA ANPAD, 20., 2002, Campinas. Anais... Campinas: ANPAD, 2001.
MASON, E.

Price and production policies of large scale enterprise. The American Economic Review, Supplement 29, p. 61-74, 1939.

The current state of the monopoly problem in the United States. Harvard Law Review, v. 62, p. 1265-85, 1949.

McGAHAN, A. M.;

PORTER, M.

How much does industry matter, really? Strategic Management Journal, v.18, Summer Special Issue, p.15-30, 1997.

MELLO, R.;

CUNHA, C.

A natureza e a dinâmica das capacidades organizacionais no contexto brasileiro: uma agenda para pesquisas sobre a vantagem competitiva das empresas brasileiras. In: ENCONTRO ANUAL DA ANPAD, 20., 2002, Campinas. Anais... Campinas: ANPAD, 2001.

MILLIKEN, G;

JOHNSON, D.

Analysis of Messy Data. Vol. I: Designed Experiments. New York: Von Nostrand Reinhold Company, 1984.

\section{OSTER, S.}

Modern competitive analysis. New York: Oxford University Press, 1990.

\section{PEREIRA, S.}

Análise da relação entre valor e alavancagem no mercado brasileiro. In: ENCONTRO ANUAL DA ANPAD, 24., 2000, Florianópolis. Anais... Florianópolis: ANPAD, 2000. 
PERIN, M.;

SAMPAIO, C.

Performance empresarial: uma comparação entre indicadores subjetivos e objetivos. In: ENCONTRO ANUAL DA ANUAL DAANPAD, 23., 2002, Foz do Iguaçu. Anais... Foz do Iguaçu: ANPAD, 1999.

\section{PETERAF, $\mathrm{M}$.}

The cornerstones of competitive advantage: a resource-based view. Strategic Management Journal, v. 14. p. 179-191, 1993.

PORTER, $M$.

Competitive strategy: techniques for analyzing industries and competitors. New York: Free Press, 1980.

RUMELT, R.

How much does industry matter? Strategic Management Journal, v.12. p. 167-185, 1991.

RUMELT, R.;

SCHENDEL, D.;

TEECE, D.

Fundamental issues in strategy. Cambridge: Harvard Business School Press, 1994.

SCHERER, F.;

ROSS, D.

Industrial Market Structure and Economic Performance. Chicago: Rand McNally \& Company, 1980.
SCHMALENSEE, $\mathrm{R}$.

Do markets differ much? The American Economic Review, v. 75, p. 341-351, 1985.

SMITH, K. G.;

GRIMM, C. M.;

WALLY, S.

Strategic groups and rivalrous firm behavior: towards a reconciliation. Strategic Management Journal, v.18, n.2, p.149-157, 1997.

THOMAS, H.;

VENKATRAMAN, N.

Research strategic groups: progress and prognosis. Journal of Management Studies, v.25, n.6, p. 537555, 1988.

VASCONCELOS, F.;

CYRINO, A.

Vantagem competitiva: os modelos teóricos atuais e a convergência entre estratégia e teoria organizacional. Revista de Administração de Empresas, v. 40, n. 4, 2000.

WERNEFELT, B.

A resource-based view of the firm. Strategic Management Journal. v. 5, p. 171-180, 1984. 